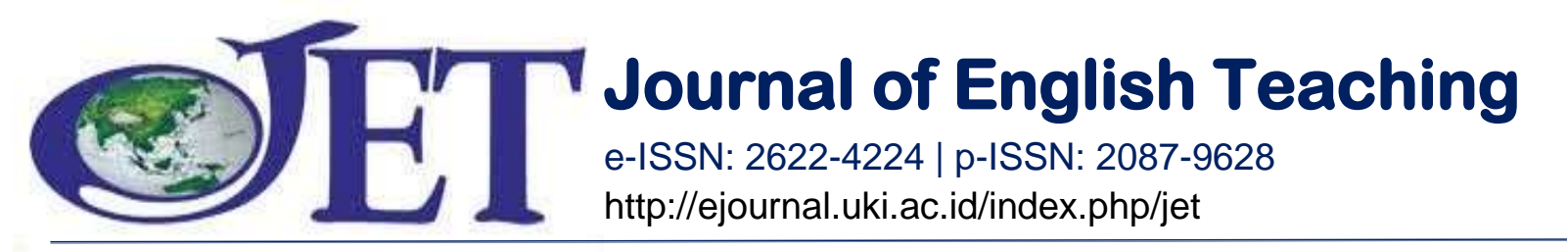

\title{
Enhancing Academic Writing Skills through Mini Revision Lessons and Feedback
}

\section{Jigme Dorji}

jigmedorji16@education.gov.bt

Phuentsholing HSS, Bhutan

\begin{abstract}
An action research was conducted with class 12 science students $(n=15)$ for three months with an aim of helping students improve their academic writing skill through mini revision lessons and feedback. The study was conducted based on pre-test-intervention-post-test design using mixed method. Test scores and interview were two main data collection tools. Data collected from test scores were analysed descriptively in percentage and average. Answers to interview questions were analysed thematically. Finding from the study revealed that students' quality of writing improved proving the effectiveness of mini revision lessons and feedback.
\end{abstract}

\section{Keywords:}

academic writing, revision, feedback

\section{How to cite:}

Dorji, J. (2021). Enhancing Academic Writing Skills through Mini Revision Lessons and Feedback. Journal of English teaching, 7(1), 56-66. DOI:

https://doi.org/10.33541/jet.v7i1.2272

\section{INTRODUCTION}

Choeda, Wangchuk and Gyeltshen (2020) state that "the quality of students' academic writing has been affected by inadequate knowledge of grammar or language rules" (p. 1). However, students also need to be provided with enough guidance in the layout, features and content and language conventions of the academic writing. Therefore, an action research titled Enhancing Academic Writing Skill Through Mini Lessons and Revision was carried out to bring improvement in students' academic writing skill by providing mini lessons and feedback on their writing. 
This study is an action research, which is defined by Mills (2007) as "any systematic inquiry conducted by teacher researchers, principals, school counsellors, or other stakeholders in the teaching/learning environment to gather information about how their particular schools operate, how they teach, and how well their students learn" (p. 5). Pardede (2017) accentuated that action research "is about how teachers as practitioners obtain knowledge through their practices and use the knowledge to improve their teaching skills" (p. 138). Employing the action research cycle proposed by Kemmis and McTaggart (1990), this action research aimed at exploring strategies for improving the academic writing skill and enhancing the academic writing skill of students through mini revision lessons and feedback. Test result and interview were used as the main data collection tools.

\section{Reconnaissance}

Reconnaissance is defined as a preliminary information gathering consisting of analysis of the situation, competence of the teacher researcher and the participants, and literature review (Royal Education Council, 2018, p. 8). Consequently, situation of the practising school is analysed, competence of the teacher researcher and the participating students is described, and various literature related to the topic of intervention is reviewed.

\section{Situational analysis}

Situational analysis is a situation when a researcher critically assesses the realities of the current situation he or she is in and wants to improve upon his or her practices (Royal Education Council, 2018, p.8).

The participants in this action research were one section of class twelve Science students $(n=15)$ of one Higher Secondary School in Bhutan. In Bhutan, it is compulsory for students to pass in English examinations for them to qualify for the next grade. Therefore, students from class 8 till class 12 are conducted with English examinations in two papers. For class 12 students, English I comprises of writing an essay and writing a short story both weighing 30 marks each. Nature of language and grammar carries 10 marks and 30 marks respectively.

In the practising school, students are found scoring lower in essay in comparison to writing short story. Comparison is made between writing essay and writing short story because they are under the category of writing in English I.

Figure 1 in the Pre-Intervention: Baseline Data section shows marks scored by the students during their essay writing test. The highest is 20 out of 30 while the lowest is 10 . The mean average of $49.3 \%$ is $9.3 \%$ higher than the pass percentage which is $40 \%$. However, it is a worrying situation for the researcher demanding immediate strategic intervention.

\section{Competence}

The researcher has been teaching English for different class levels ranging from preprimary to class twelve for the last eleven years. Moreover, this is his third year teaching class 12 students. Thus, the researcher understands the importance of English for students to qualify for the next grade. In particular, the researcher recognizes the significance of scoring higher in their essay writing. Similarly, students have been studying English ever since their pre-primary classes as their major subject. They know the importance of English. 


\section{LITERATURE REVIEW}

There are various approaches to enhancing the academic writing skill of students. Accordingly, teachers adopt different strategies. In a recent study, Shammout (2020) investigated if cooperative learning activities enhanced writing skills of Syrian EFL learners at Arab International University. Besides enhancing writing performance, EFL students in the cooperative learning ambience managed to foster the linguistic competence of students (p. 791). Out of nine impressive tips for improving academic writing skills, Smith (2018) shares practise on reading and writing and focussing on planning and structuring as the two main tips for academic writing skill. However, it is only with the implementation of right strategies the academic skill of students will be enhanced. Similarly, Baker (2016) conducted a study to examine if peer review as a strategy was effective for improving the quality of students' writing. The study which drew from a peer-review assignment conducted over 3 years in upper-division, disciplinespecific courses, revealed the importance of assessing the peer-review process in upscaling students' writing skills (p. 179).

Besides various approaches, there are number of studies conducted by numerous researchers specifically on the impact of revision and feedback on the academic writing skill of students. Fitzgerald (1987) states that revision is central and inevitable part of writing because when writers use revision to rework thoughts and ideas, it powerfully affects writers' knowledge (p. 481). Although the amount of research on revision is still inadequate, Fitzgerald (1987) asserts that a "growing body of knowledge accumulated from a set of diverse methodologies is beginning to inform us about the process of revision and about writers' revision efforts" (p. 481).

In 1993, Stoddard and MacArthur investigated the effectiveness of "an approach to improving revising skills that integrated strategy instruction, peer response, and word processing" (p. 76). The study which involved seventh and eighth grade students with learning disabilities showed the overall quality of final drafts increasing substantially from pre-tests to post-tests (p. 76). Similarly, Helfers, C., Duerden, S., Garland, J. \& Evans, D. L. (1999) conducted a study to explore if peer revision method was effective for engineering students in first-year English courses. The result of the study presented a guided peer revision tool that can be adapted for any assignment which enables student writers to act as effective peer reviewers (p. 6).

In 2007, Saddler and Asaro conducted a study with six second-grade students to examine whether supplemental writing instruction in planning and revising improved the story writing skills of students with learning disabilities (LD). The researchers found out that the participants wrote post-instruction stories that were longer, more complete grammatically, and qualitatively better (p. 223). In order for revision to be effective, Saddler and Asaro (2007) also recommend that students must be taught why they needed revision (p. 232).

Likewise, Butler and Britt (2011) conducted a study on the effectiveness of written tutorials (argument tutorial and global revision tutorial) in improving the writing skills of the students. The researchers mention that both argument tutorial and global revision tutorial assisted students in improving their revisions, and the tutorials were completed independently by the students successfully (p. 70). Such tutorials can be used as a supplement to large classes in various disciplines and by students themselves to help their own writing (Butler \& Britt, 2011, p. 89).

A study was conducted by Hanjani and Li in 2014 to investigate EFL students' interactional dynamics during a collaborative revision activity with five pairs of EFL 
learners enrolled in an L2 essay-writing course at an Iranian university. Each pair attended one collaborative revision session during which they jointly revised their argumentative texts. The participants' interactions were collected during collaborative revision and their revised drafts. Findings suggest that collaborative revision can be incorporated in EFL writing pedagogy as a method to improve writing and revision skills (p. 101).

Riddell (2015) states that the revision process can be valuable and improve the quality of essays under certain conditions (p. 86). Riddell's study conducted in 2015 involving $\mathrm{n}=68$ students stated that participants experienced an increase in their perceptions of value of the revision process, and particularly revision through careful and critical feedback (p. 86). The study concludes that the richer understanding of essay writing as a process that develops over time can be improved through feedback and attentive revisions (p. 87).

O'Neill and Gravois (n.d.) conducted a study to assess whether a focus on revision was effective in improving students' writing skills. The study which presented two approaches from two disciplines - Business Communication and Marketing - concluded that a focus on revision can improve both motivation and performance of students as writers (p. 8).

With regard to feedback, Nakanishi (2007) conducted a study on the effects of different types of feedback and revision with forty Japanese EFL learners. The finding from the study was that the scores of all groups became higher after each type of feedback, and there was no noteworthy difference according to feedback types (p. 213). Another similar study was conducted in 2016 by Silva, Almeida and Farroupas. In their experimental study which involved 45 children of the $4^{\text {th }}$ grade, children from experimental group 1 and 2 improved in the quality of their spelling and the cohesion of their texts (p. 26).

Dysthe (2011) conducted a case study of feedback practices in the first year of a two-year master's programme. The empirical data which consisted of a text corpus of students' essays and teachers' comments, supplemented by interviews, recommended the necessity of considering carefully teacher's feedback on writing skills enhancement ( $\mathrm{p}$. 140). Correspondingly, Maarof, Yamat and Li (2011) conducted a study to examine ESL students' perception of the role of teacher, peer and combined teacher-peer feedback in ESL writing. The result of the study which involved 150 students from five secondary schools in Malaysia showed that most of the students welcomed the combined use of teacher and peer feedback in ESL writing (p. 29). The researchers concluded that the combination of teacher feedback and peer feedback in ESL writing may "not only possibly help increase immediate writing abilities, but also help promote durability of the skill" (p. 33).

Nagode, Pizorn and Jurisevic (2014) conducted a study to explore the role of written corrective feedback in developing writing in L2. Findings from the study showed the effectiveness of feedback in developing writing skill of L2 learners (p. 89). In 2019, Karim and Endley conducted a study to discover the effects of direct and indirect written corrective feedback. Conclusions from the study revealed that the written corrective feedback considerably reduced learners' mistakes in their subsequent revision tasks ( $\mathrm{p}$. 68). Similarly, Amoli (2020) conducted a study on the effect of oral metalinguistic corrective feedback on learners' knowledge of pronoun with 74 Iranian EFL learners. Results from the study discovered the success of the intervention action (p. 672).

The studies conducted on the effectiveness of revision and feedback proved to be successful in upscaling the academic writing skill of students. However, these were in the 
context of outside Bhutan. Thus, the question of whether these two strategies will be effective in the Bhutanese classroom setting captured the attention of the researcher.

\section{ACTION RESEARCH QUESTION}

The action research question of this study was:

How can academic writing skill of class twelve students be enhanced?

\section{Aims of the Action Research}

Besides the main action research question, this study aimed at:

1. Exploring strategies for enhancing the academic writing skill of students.

2. Enhancing the academic writing skill of students.

\section{RESEARCH DESIGN AND METHODOLOGY}

This action research was conducted with class 12 science students $(n=15)$ of one Higher Secondary School in Bhutan. The study was based on pre-test-intervention-post-test design based on convenience sampling method. The main data collection tools of this study were test result and interview. Mixed method was used to analyse the data. Result derived from the essay writing test was analysed descriptively in percentage and average and answers to the interview questions were analysed thematically. Essay writing test was conducted twice, once before and once after the intervention process. However, interview was conducted once after the intervention action.

During the pre-intervention, students were conducted with a test on writing an argumentative essay. The essay was evaluated based on the essay evaluation criteria set by Bhutan Council for School Examination and Assessment (BCSEA). BCSEA is an autonomous assessment body in Bhutan that assesses the students in different spheres of learning through the most credible trends. Students' scores are presented in percentage and average.

During the intervention process, the researcher used two main tools as intervention strategies. They were mini revision lessons based on the features of an argumentative essay and language and grammar and feedback on students' writing. This intervention action lasted for three months from mid of July till mid of September.

Following the intervention action, students were conducted with essay writing test. Like during the baseline data collection, essay was evaluated based on the essay evaluation criteria set by BCSEA and the scores were described in percentage and average.

After the comparative analysis of results of two rounds of tests, students were conducted with an interview each. The interview was conducted mainly to ascertain with the findings from the study, and to gather their perceptions about the intervention process.

\section{Pre-Intervention: Baseline Data}

The pre-intervention data of this study was the score of students during their essay writing test. Essay writing was assessed on three major areas. They were layout, features and content and language conventions carrying 5, 15 and 10 marks each. Students' total score out of 30 is presented in the figure 1.

Figure 1 summarizes students' score during the baseline data collection. Students' errors were spread in all the areas of assessment. There were inconsistent paragraphing, 
handwriting was illegible, arguments though presented were disorganized and many students committed spelling errors more than 10 times.

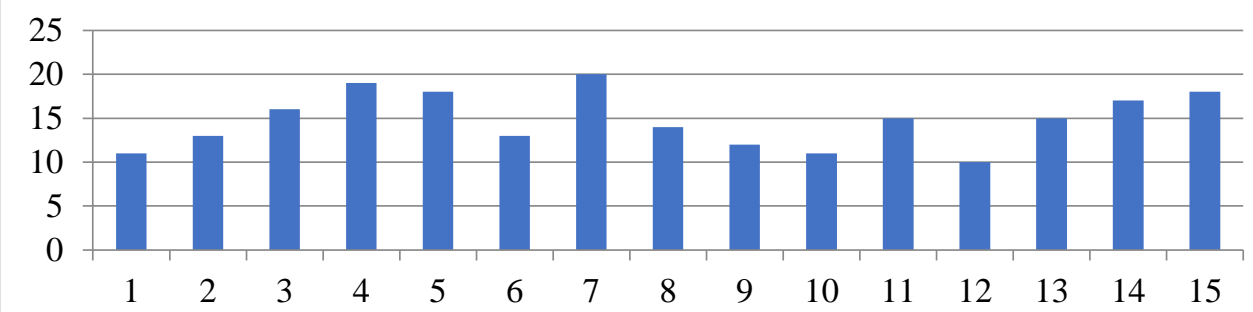

Figure 1. Students' score during baseline data.

As portrayed in the figure above, the highest a student has scored is 20 out of 30 while the lowest in the class is 10 out of 30 which are $66.6 \%$ and $33.3 \%$ respectively. Out of 15 students, 1 student managed to score 20 while there were 8 students who scored 15 and below. Since the class average mark was $49.3 \%$, it was a disquieting trend for the researcher.

\section{Intervention}

With students' average score of $49.3 \%$ and 8 students scoring 15 or below out of 30 during their essay writing test, baseline data disclosed class twelve students' weakness in writing essay. This data recommended the researcher to intervene immediately with tactical strategies for students to excel in academic writing. Thus, the idea of mini revision lessons on features of argumentative essay and language and providing feedback on students' writing came into consideration.

\section{Mini Revision Lessons}

No matter how much students studied, revision is crucial for them to score high during the examinations. The entire study effort goes into waste without a proper and efficient revision. Thus, during the intervention, the researcher carried out with revision lessons on writing argumentative essay. The lessons were based on the BCSEA criteria. BCSEA assesses argumentative essay in three broad areas. The first is layout which carries 5 marks out of 30. In the layout, students must derive and write a title for the essay. Paragraph format of the essay should be uniform throughout and students' essay must be neat and clean.

The second area of assessment is features and content of the essay. Along with the introduction to the essay, suitability of students' thesis statement is assessed. Organization of the presentation of arguments and the conclusion of the essay are the other sub-areas of assessment.

The final area of assessment is language conventions under which students are assessed on language register, general accuracy of language and vocabulary and spelling. Mini revision lessons were conducted with students based on these areas for three months.

\section{Feedback}

Dorji: Enhancing Academic Writing Skills through Mini Revision Lessons and Feedback https://doi.org/10.33541/jet.v7i1.2272 
Along with mini revision lessons, students were provided with feedback. In his blog post, DeFranzo (2015) opines that feedback can motivate and improve performance of students. Thus, students were provided with both written and oral feedback. Feedback was provided as and when the mini revision lessons were conducted. The nature of feedback, whether oral or written, depended on the topic the researcher covered during the revision lesson. Mini revision lessons were conducted for three months and so was feedback.

\section{Post-Intervention}

After the intervention action was completed, students were conducted with another essay writing test. In similar fashion to the pre-intervention, students were conducted with writing of an argumentative essay. Their score is presented in the following figure.

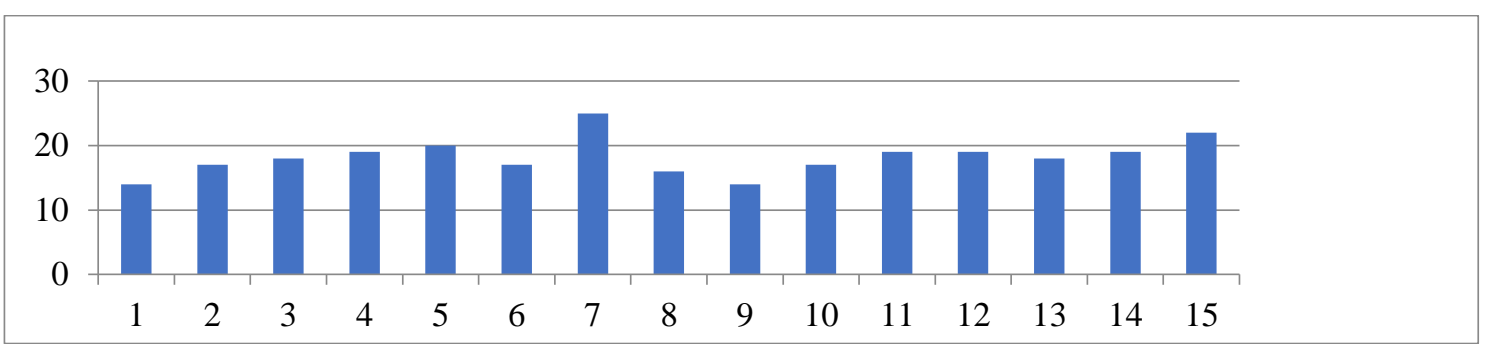

Figure 2. Students' score post-intervention.

Figure 2 is an explanation about students' score during the post-intervention. In comparison to pre-intervention test, students made progress during their post-intervention test. There was not a single student whose spelling error was more than 10 . There were some students whose paragraphs were inconsistent. But students have presented their arguments better during the post-test in comparison to their pre-test.

As mentioned in Figure 2, the highest a student has scored is 25 out of 30 while the lowest in the class is 14 out of 30 which are $83.3 .6 \%$ and $46.6 \%$ respectively. Out of 15 students, 3 students managed to score 20 and above. There is no student who scored 15 and below. The class average mark is $60.8 \%$.

\section{RESULTS AND DISCUSSION}

In order to present the findings of this study, it is worthwhile revisiting the aims of this action research. This study aimed at:

1. Exploring strategies for enhancing the academic writing skill of students.

2. Enhancing the academic writing skill of students.

The first aim of this action research was fulfilled during the intervention process. In general, the first aim targeted at exploring strategies for enhancing the academic writing skill of students. Thus, as it was discussed in detail in the Intervention section, two main strategies were explored by the researcher to enhance the academic writing skill of 
students. They were mini revision lessons on features of essay and language and providing feedback on students' writing.

The second aim of this action research was to enhance the academic writing skill of students. Therefore, the success in enhancing the academic writing skill of students with the use of researcher's strategies is explained below with the help of the two main data collection tools.

\section{Test Result}

Test was one main data collection tool in this action research. Two rounds of essay writing tests were conducted, once before and once after the intervention action. Data collected from the test were analysed descriptively in percentage and average. The following figure reflects the comparative analysis of the tests conducted pre and post-intervention.

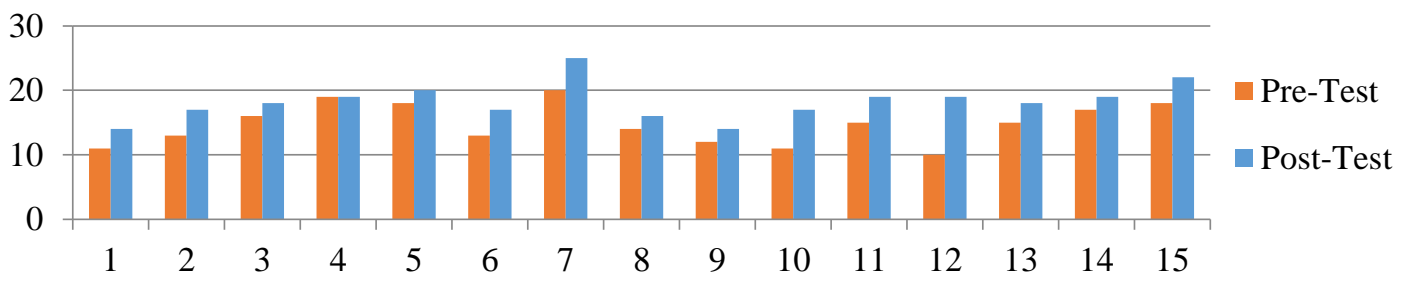

Figure 3. Students' score pre and post-intervention.

Figure 3 presents comparison of students' score pre and post-intervention. Students' average score of $49.3 \%$ during the pre-intervention was a worrying trend for the researcher. However, the situation improved to $60.8 \%$ during the post-intervention test. An increase of $11.5 \%$ from pre-intervention to post-intervention was a satisfying result for the researcher. This proved the success of the researcher's intervention strategies. To discuss further, 1 student scored 20 and above during the pre-intervention but 3 students scored 20 and above during the post-intervention. In similar manner, there were 8 students whose scores were 15 and below during the pre-intervention. However, none of the students fell in the category of 15 and below post-intervention. These prove the success of the researcher's intervention strategies.

Finally, test result as one data collection tool showed the aim of enhancing academic writing skill of students as fulfilled.

\section{Interview}

Comparison of test scores pre and post-intervention strategies demonstrated the success of the researcher's intervention strategies. An increase of an average of $11.5 \%$ from $49.3 \%$ to $60.8 \%$ from pre to post-intervention was noteworthy. However, the researcher conducted interview with the students to verify whether their views run in parallel with the improved test result during the post-intervention. The other aim of the interview was to gather their perceptions about the intervention strategies. The unstructured interview questions revolved around students' views and perceptions about the efficacy of the researcher's intervention strategies. Data gathered from interview were analysed thematically. 
The first theme derived from the interview was the importance of language and grammar in upscaling academic writing skill. One student noted that grammar and language are the two important essence of academic writing skill. On the similar front, another student expressed that his low score in the essays was due to his weakness in grammar and language. To further cement their views, one student has written:

If we want to score high in essay, we must be good in grammar and language. Otherwise, our dream of scoring high in essay will remain as a dream.

Therefore, it is essential for English teachers to provide students with enough practice on grammar and language.

One interview question demanded students' views on whether feedback from the researcher helped them in scoring higher. The answer was 'yes' from all the students. Feedback kept students on track at first and later motivated them to work more thus leading to increase in their scores. Students recommended teachers to provide constant feedback so that the students are kept motivated. Students' view on the importance of feedback corresponds with the findings from a study conducted by Mamoon-Al-Bashir, Kabir and Rahman (2016). They state that feedback provides evidence about progress and achievement of students thus motivating them to work further more (p. 39). Similarly, a study conducted by Banerjee in 2014 states that feedback is the key turning point in "effecting student's learning" (p. 36). During the intervention process, students were provided with feedback on their writing styles, legibility of their handwriting and maintenance of constant paragraphing thus improving their scores during the postintervention.

The final idea consequent of the interview was the importance of constant revision. Routinely engaging students in revision is associated with better performance and it is likely that giving students greater opportunity to revise will lead to improved writing skills (Eli Review, n.d.). Students reported that revision takes them back to what was taught long before and in this process, they can study even if they have not understood during the normal teaching. This is similar to a post by Genie Tutors (2018). The blog post posits the twofold significance of revision. Firstly, revision helps remember facts, figures and topics that were covered some time ago. Secondly, revision helps increase confidence, and reduces anxiety.

The three themes derived from the students' answers to the unstructured interview questions ascertain with the increased trend of students' essay test result postintervention. Thus, interview as the other data collection tool displays the aim of enhancing academic writing skill of students as achieved.

\section{CONCLUSION}

The primary question of this action research was: How can academic writing skill of class twelve students be enhanced? The academic writing skill of students was enhanced with the researcher's apt application of strategies. The two strategies applied were mini revision lessons on review of features of essay and language and grammar and feedback on writing.

There was an increase of class test average from $49.3 \%$ to $60.8 \%$ during the postintervention. The three themes derived from the interview such as the importance of language and grammar, significance of revision and vitality of feedback ascertain with 
the increased result of students. The two data collection tools, test result and interview, reflected the effectiveness of the researcher's intervention strategies.

In general, this action research was carried out effectively as the planned actions were implemented on time according to the timeline. Most importantly, the significance of mini revision lessons and feedback is revealed. The result of this action research is in concurrent with one blog post about the significance of providing feedback for students' academic success. actiTIME (2018) states that besides promoting personal and professional growth, feedback provides criticism and allows to see what everyone can change to improve their focus and results.

\section{Limitations}

There are limitations to this study. The first limitation is sample size of 15 students. The result of this study would have been more valid to the general mass if the participants were of larger size. The author could not take on a critical friend to authenticate the data. This is another limitation to this action research.

\section{REFERENCES}

actiTIME. (2018). The Importance of Feedback. Retrieved from https://www.actitime.com/project-management-/importance-of-feedback/ on 30 June 2020.

Amoli, F. A. (2020). The Effect of Oral Metalinguistic Corrective Feedback on Learners' Knowledge of Pronoun among Iranian EFL Learners. Theory and Practice in Language Studies, 10 (6), 672 - 677.

Baker, K. M. (2016). Peer Review as a Strategy for Improving Students' Writing Process. Active Learning in Higher Education. 17 (3), 179 - 192.

Banerjee, A. (2014). Improving Student's Learning with Corrective Feedback: A Model Proposed for Classroom Utility. International Journal of Education and Psychological Research (IJEPR), 3(4), 36 - 40.

Butler, J. A. \& Britt, M. A. (2011). Investigating Instruction for Improving Revision of Argumentative Essays. Written Communication. 28 (1), 70 - 96.

Choeda, Wangchuk, T. \& Gyeltshen, T. (2020). Enhancing Academic Writing Skill of B. Ed Arts Students: An Action Research at Samtse College of Education. Conference paper.

DeFranzo, S. E. (2015). 5 Reasons Why Feedback is Important. Retrieved from: https://www.snapsurveys.com/blog/5-reasons-feedback-important/ on 30 June 2020.

Dysthe, O. (2011). 'What is the Purpose of Feedback when Revision is not Expected?' A Case Study of Feedback Quality and Study Design in a First Year Master's Programme. Journal of Academic Writing. 1 (1), 135 - 142.

Eli Review. (n.d.). Revision and Learning. Retrieved from: https://www.elireview.com/learn/research/revision/ on 30 June 2020.

Fitzgerald, J. (1987). Research on Revision in Writing. Review of Educational Research. $57(4), 481-506$.

Genie Tutors. (2018). The Importance of Revision. Retrieved from: https://www.genietutors.co.uk/the-importance-of-revision/ on 30 June 2020.

Hanjani, A. M. \& Li, L. (2014). Exploring L2 writers' collaborative revision interactions and their writing performance. Science Direct. 44, $101-114$.

Dorji: Enhancing Academic Writing Skills through Mini Revision Lessons and Feedback

https://doi.org/10.33541/jet.v7i1.2272 
Helfers, C., Duerden, S., Garland, J. \& Evans, D. L. (1999). An effective peer revision method for engineering students in first-year English courses. FIE'99 Frontiers in Education. 29th Annual Frontiers in Education Conference. Designing the Future of Science and Engineering Education. Conference Proceedings. 3 (1), 6 - 12.

Karim, K. \& Endley, M. J. (2019). Should Feedback be Direct or Indirect? Comparing the Effectiveness of Different Types of WCF on L1 Writers' Use of English Prepositions. Language Teaching and Research Quarterly, 13 (1), 68 - 84.

Kemmis, S., \& McTaggart, R. (1990). The action research planners. Victoria: Deakin University Press.

Mamoon-Al-Bashir, Kabir, R. \& Rahman, I. (2016). The Value and Effectiveness of Feedback in Improving Students' Learning and Professionalizing Teaching in Higher Education. Journal of Education and Practice, 7 (16), 38 - 41.

Maarof, N., Yamat, H. \& Li, K. L. (2011). Role of Teacher, Peer and Teacher-Peer Feedback in Enhancing ESL Students' Writing. World Applied Sciences Journal. $15(1), 29-35$.

Mills, G. E. (2007). Action research: A guide for the teacher researcher (3rd Ed.). Upper Saddle River, N.J.: Pearson Education, Inc.

Nagode, G. P., Pizorn, K. \& Jurisevic, M. (2014). The Role of Written Corrective Feedback in Developing Writing in L2. English Language and Literature Teaching, $1(1), 89-\quad 98$.

Nakanishi, C. (2007). The Effects of Different Types of Feedback on Revision. The Journal of Asia TEFL. 4 (4), 213 - 24.

O’Neill, K. S. \& Gravois, R. (n.d.). Using a focus on revision to improve students' writing skills. Journal of Instructional Pedagogies. 19 (1), 1 - 12.

Pardede, P. (2017). Action Research in EFL Learning and Teaching. In: PROCEEDING English Education Department Collegiate Forum (EED CF) 2015-2018. UKI Press, Indonesia, Jakarta, pp. 136-146.

Riddell, J. (2015). Performance, Feedback and Revision: Meta-cognitive Approaches to Undergraduate Essay Writing. Collected Essays on Learning and Teaching. 8 (1), $79-96$.

Royal Education Council. (2018). A Guide to Action Research: Enhancing Professional Practice of Teachers in Bhutan. Thimphu, Bhutan: Royal Education Council.

Saddler, B. \& Asaro, K. (2007). Increasing Story Quality Through Planning and Revising: Effects of Young Writers With Learning Disabilities. Learning Disability Quarterly, 30 (1), 223-234.

Shammout, M. (2020). The Effect of Cooperative Learning Activities on Enhancing the Writing Skills of Syrian EFL Learners at Arab International University. Theory and Practice in Language Studies, 10 (7), 791-797.

ilva., Almeida, T. \& Farroupas, S. (2016). The Impact of Revision and Feedback on the Quality of Children's Written Compositions. International Journal of Social Sciences \& Educational Studies, 3 (2), $26-42$.

Smith, E. (2018). 9 Tips for Improving Academic Writing Skills. Retrieved from: https://www.google.com/amp/s/academicwritingpro.com/blog/9-practical-forimproving-your-academic-writing on 30 June 2020.

Stoddard, B. \& MacArthur, C. A. (1993). A Peer Editor Strategy: Guiding LearningDisabled Students in Response and Revision. Research in the Teaching of English. 27 (1). 76-103. 